\title{
Método de determinação da área foliar da cultivar de batata Ágata a partir de dimensões lineares ${ }^{1}$
}

\section{Method of determination of the leaf area of the potato cultivar Ágata from linear dimensions}

\author{
Sidnei Osmar Jadoski²; Edina Cristiane Lopes ${ }^{3}$; Marcio Furlan Maggi ${ }^{4}$; \\ Adriano Suchoronczek ${ }^{5}$; Larissa Romão Saito ${ }^{6}$; Sergio Denega ${ }^{7}$
}

\begin{abstract}
Resumo
A cultivar Ágata é atualmente a mais cultivada nas lavouras de produção de batata no Brasil, contudo, ainda são necessárias informações básicas sobre suas características, especialmente sobre o desenvolvimento do dossel vegetativo.O trabalho foi desenvolvido em área experimental da Unidade de Pesquisa em Bataticultura e Microclima para a Agricultura, no Departamento de Agronomia da Universidade Estadual do Centro Oeste, em Guarapuava-PR. O objetivo foi avaliar a eficiência do ajuste de diferentes modelos matemáticos para determinação da área foliar de plantas de batata da cultivar Ágata. As avaliações foram realizadas considerando as dimensões de 100 folhas de diversos tamanhos, que foram coletadas aleatoriamentena fase de máximo desenvolvimento vegetativo das plantas. Os dados obtidos foram submetidos a analise de regressão, sendo testados seis diferentes modelos matemáticos: função linear, quadrática, cúbica, e os modelos exponenciais de crescimento, Gauss e Lorentz, utilizando o comprimento e a largura de folhas como variável independente para o ajuste em função da área foliar real medida em laboratório. A variável comprimento e o produto do comprimento $x$ largura da folha foram as que apresentaram os melhores resultados de ajuste aos modelos testados. Com maior ênfase para o comprimento, para o qual todos os modelos testados apresentaram significância estatística. Concluiu-se que o comprimento da folha é o parâmetro mais adequado para ser utilizado em avaliações da área foliar de plantas de batata cv. Ágata, sendo a função exponencial de crescimento e Lorentz as menos recomendadas devido aos menores coeficientes de ajuste.

Palavras-chave: Solanumtuberosum, índice de área foliar, determinação não destrutiva
\end{abstract}

\begin{abstract}
The cultivar Ágata is currently the most widely cultivated in areas of potato production in Brazil, however, are necessaries basic information about its characteristics, especially on the development of the canopy. The work was developed in experimental area of the Unit of Research in Potato Culture and Microclimate for Agriculture, in the department of Agronomy of the UniversidadeEstadual do Centro Oeste (Unicentro), in Guarapuava (PR). The aim was to evaluate the efficiency of the adjustment of

\footnotetext{
${ }^{1}$ Parte de Dissertação de Mestrado do segundo autor apresentada ao Programa de Pós-Graduação em Agronomia, PPGA da Universidade Estadual do Centro-Oeste.

${ }^{2}$ Eng $^{\circ}$. Agr ${ }^{\circ}$, Prof. Dr. Associado, Dept ${ }^{\circ}$ de Agronomia, Universidade Estadual do Centro Oeste, UNICENTRO. Guarapuava, PR. E-mail: sjadoski@unicentro.br

${ }^{3}$ MSc. Agronomia. UNICENTRO e Doutoranda em Agronomia, UFPR. E-mail: edinacristiane@hotmail.com

${ }^{4}$ Eng $^{\circ}$. Agrícola, Prof. Dr. Adjunto do Centro de Exatas e Tecnológicas, Universidade Estadual do Oeste do Paraná, UNIOESTE. Guarapuava, PR. E-mail: mmaggi@unioeste.br

${ }^{5}$ Discente de Agronomia da UNICENTRO. Guarapuava, PR. E-mail: adrianos@unicentro.br

${ }^{6}$ MSc. Agronomia da UNICENTRO. E-mail: 1saito@unicentro.br

${ }^{7}$ Eng $^{\circ}$ Dr. Setor Agrometeorologia, DEAGRO/UNICENTRO. Guarapuava, PR. E-mail: sdengea@unicentro.br

* Autor para correspondência
} 
different mathematic models to determine the leaf area of potato plants of the cultivar Ágata. The evaluations were performed considering the dimensions of a 100 seeds of several sizes which were randomly collected in the phase of maximum vegetative development of plants. The data obtained were submitted to analysis of regression, being tested six different mathematic models: linear, quadratic, cubic functions and the exponential models from growth, Gauss and Lorentz, using the length and the height of leaves as independent variable to the adjustment in function of the real leaf area measured in laboratory. The variable length and the product of length $\mathrm{x}$ width of the leaf were those who presented the best results of adjustments to the models tested. With more emphasis to the length, for which all the models testes present statistical significance. It was concluded that the leaf length is the most appropriated parameter to be used in evaluation of the leaf area of potato plants cultivar Ágata, being the exponential function of growth and Lorentz the less recommended since its lowest adjustment coefficient.

Key words: Solanumtuberosum, leaf area index, non destructive determination

\section{Introdução}

A batata (Solanumtuberosum L.) pertence a família Solanaceae, é originária da Cordilheira dos Andes, atualmente é a quarta cultura na ordem de importância no mundo, depois do trigo, arroz e milho (JADOSKI et al., 2009; BOSCO et al., 2010), sendo atualmente um dos principais alimentos da humanidade.Dellai et al. (2005) destacam que a batata é considerada a principal hortaliça do Brasil, tanto em área cultivada como em preferência alimentar.

Os estudos da fisiologia do crescimento das culturas requerem a estimativa da área foliar ao longo do ciclo de cultivo. A área foliar é uma característica importante na avaliação da eficiência fotossintética das plantas, na determinação de danos bióticos e abióticos, na análise de crescimento, relacionado com o acúmulo de matéria seca, metabolismo da planta, produção final, qualidade e maturação das culturas (BUSATO et al., 2009). Zucareli et al. (2010) salientam dados de pesquisa onde é considerado que a análise de crescimento de comunidades vegetais é um dos primeiros passos na análise de produção primária, sendo caracterizada como a ligação entre o registro do rendimento das culturas e características dos índices fisiológicos. Dentre as análises mais utilizadas, encontra-se o Índice de área foliar (IAF).

O IAF expressa a razão entre a área foliar existente na planta e a área de solo por ela ocupada. Para Nunes et al. (2006) este índice descreve a dimensão do sistema assimilador de uma cultura, onde o maior valor de IAF indica maior área foliar para interceptação da radiação solar e, dentro de determinados limites, pode estar associado a um maior crescimento da planta e produção de tubérculos.

A estimativa da área foliar pode ser realizada através de métodos destrutivos e não destrutivos. Malagi et al. (2011) descrevem que os métodos destrutivos são mais simples e precisos. Contudo, Lopes et al. (2004) acrescentam que a destruição da folha compromete o desenvolvimento normal da planta, muitas vezes dificultando o acompanhamento do desenvolvimento do ciclo da cultura no campo.

Os métodos considerados como não destrutivos são divididos em diretos e indiretos. Oliveira et al. (2002) salientam que os métodos diretos são precisos,sendo os resultados expressos rapidamente por meio de equipamentos portáteis, contudo, sua utilização é restrita devido ao alto custo. Os métodos indiretos, em geral demandam maior tempo e mãode-obra e são de difícil aplicação para muitas culturas, como as medições lineares em folhas ou partes dela.

De acordo com Nascimento et al. (2002), vários trabalhos têm relatado o uso de modelos matemáticos para estimar a área foliar com base nas dimensões da folha de diversas espécies, sem destruir a amostra. O que demonstra que esta técnica é uma ferramenta importante para a avaliação da área foliar. Silva, Fontes e Viana (2008), constataram que as medidas 
de comprimento e largura das folhas são parâmetros adequados para estimar a área foliar da batata cv. Cupido de forma rápida e sem a necessidade de coletar as folhas.

Fontes e Araújo (2007) observaram que o uso de medidas lineares, como o comprimento e largura das folhas em modelos matemáticos para estimar a área foliar, é uma alternativa que associa precisão e baixo custo, eliminando a necessidadeequipamentos sofisticados ou a realização de demoradas reconstruções geométricas, pois a área foliar é uma característica geralmente fácil de quantificar em tempo real, no próprio campo, sem necessidade de coletar a folha.

Algumas das características morfológicas da batata cv.Ágata foram avaliadas por Scheidt et al. (2009) que utilizaram o software Image J 1.36b for Windows para o cálculo de IAF, observando resultados que demonstram que este software mostrou-se adequado para as avaliações. Adami et al. (2007), avaliaram dois métodos diretos de medida de IAF, sendo um por meio de dimensões foliares (comprimento e largura máximos) e por imagens capturadas por maquina fotográfica digital, tendo verificado que ambos os métodos apresentaram elevada precisão de resultados.

Apesar de a cultura da batata ser bastante pesquisada, as informações inerentes à cv. Ágata ainda são restritas na literatura, o que deve estar associado ao fato de que esta é a cultivar mais recentemente inserida no sistema de produção em lavouras comerciais no Brasil. A carência de informações é mais evidente com relação à área foliar, para a qual ainda não são difundidas informações sobre modelos ajustados para determinações não destrutivas baseados na medida direta de dimensões foliares.

O objetivo deste trabalho foi avaliar a eficiência do ajuste de diferentes modelos matemáticos para determinação da área foliar de plantas de batata da cultivar Ágata, utilizando o comprimento e a largura das folhas como variável independente.

\section{Material e Métodos}

O experimento foi conduzido no ano agrícola de 2010, em área experimental da unidade de pesquisa em bataticultura e microclima para a agricultura, no departamento de Agronomia no Campus Cedeteg da Universidade Estadual do Centro Oeste - em Guarapuava - PR, localizada na latitude $25^{\circ} 23^{\prime} 36^{\prime \prime} \mathrm{S}$ e na longitude $51^{\circ} 27^{\prime} 19^{\prime}$ ' W, com altitude de aproximadamente $1025 \mathrm{~m}$. O clima regional é classificado como $\mathrm{Cfb}$ - subtropical mesotérmico úmido, de acordo com a classificação por metodologia de Köppen (1936).

A semeadura foi realizada de forma manual, no dia 30 de janeiro de 2010. Os tubérculos-semente da batata cv. Ágata utilizados foram do Tipo III (30-40 $\mathrm{mm}$ de diâmetro) segundo a classificação de Pereira e Daniels (2003), distribuídos com espaçamento de $0,25 \mathrm{~m}$ entre tubérculos e $0,80 \mathrm{~m}$ entre linhas com uma densidade de plantio de 50.000 tubérculos por hectare. As características dos tubérculos e densidade de semeadura estavam dentro de uma das alternativas de plantio mais utilizadas na região de Guarapuava.

A cobertura dos tubérculos-semente foi realizada com aproximadamente $0,18 \mathrm{~m}$ de terra, nivelando os sulcos anteriormente abertos para o plantio. A emergência das plantas ocorreu no dia 10/02/2010 aos 10 dias após o plantio (DAP). A amontoa foi realizada dia 26 de janeiro (26 DAP), com auxílio de uma enxada rotativa adaptada para tal fim.

As avaliações foram realizadas considerando as dimensões de cem folhas de tamanhos variáveis abrangendo desde os menores até os maiores tamanhos, que foram coletadas aleatoriamente na fase de máximo desenvolvimento vegetativo das plantas, entre 45 e 60 dias após a emergência. As folhas coletadas eram acomodadas em caixa térmica e conduzidas imediatamente ao laboratório visando evitar a perda de turgescência durante as determinações.

Em laboratório foram realizadas as medições de comprimento e largura de cada folha, utilizando- 
se um paquímetro digital. A largura da folha correspondeu a maior distância no sentido perpendicular ao comprimento da folha, e o comprimento foi considerado como a distância entre a base distal do pecíolo e aextremidade do terminal. Na Figura 1 é apresentada uma amostra da imagem das folhas inteiras de batata.

Figura 1. Folhas de diferentes tamanhos de plantas de batata, utilizadas para a determinação da área foliar em software ImageJ. Guarapuava-PR, 2011.

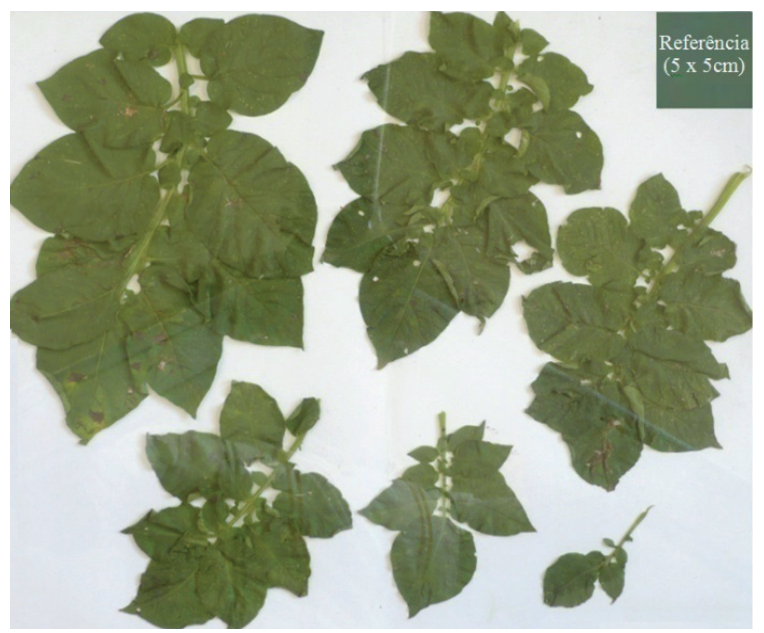

Fonte: Elaboração dos autores.

Após arealizaçãodas medidasnão destrutivascada folha foi decomposta sendo os folíolosdistribuídos em superfície contrastante de coloração branca, juntamente com uma referência de escala de 5 x 5 $\mathrm{cm}$ (Figura 2). Para a medida direta da área foliar as imagens digitais foram manuseadas utilizado o Software Image ${ }^{\circledR}$ (Powerful Image Analysis) de domínio público. Este software captura a imagem de todos os folíolos de uma folha completa e através de procedimentos de contraste de cores sendo a folha de cor escura e fundo contrastante (Figura 3) e de comparação com a escala real presente, calcula a área total real da folha.
Figura 2. Folíolos de uma folha de planta de batata utilizados para a determinação da área foliar em software ImageJ. Guarapuava-PR, 2011.

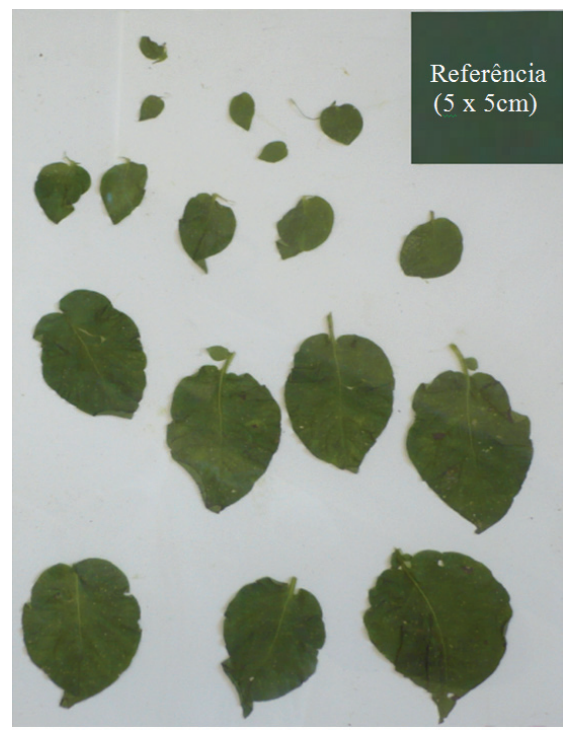

Fonte: Elaboração dos autores.

Figura 3. Folíolos de uma folha de planta de batata digitalizados com fundo contrastante utilizadas para a determinação da área foliar em software ImageJ. Guarapuava-PR, 2011.

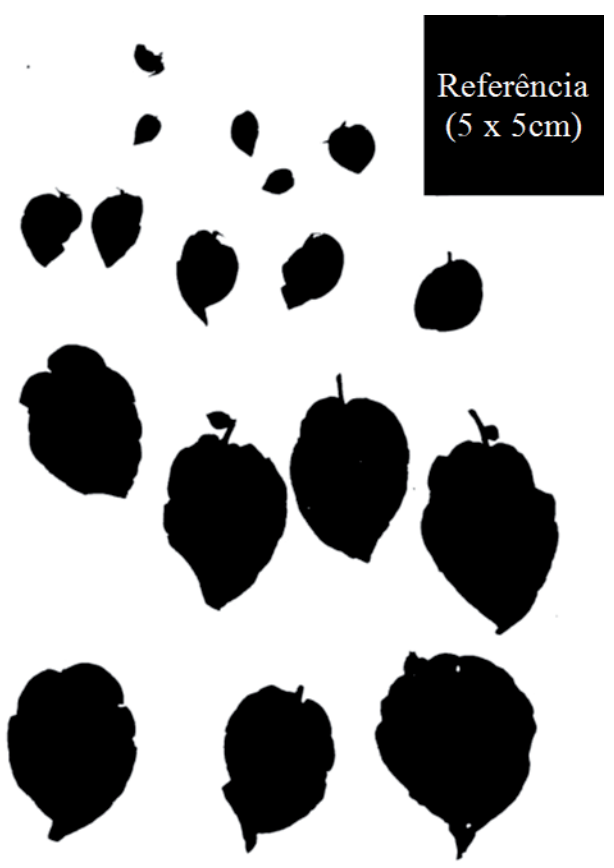

Fonte: Elaboração dos autores. 
Posteriormente, os dados de comprimento, largura e área real total de cada folha, foram tabulados e correlacionados visando a determinação de uma equação ajustada para aplicação na medida de área foliar. Inicialmente foram testados vários modelos de equações, tendo sido optado pela realização de avaliações utilizando seis modelos de equações de aplicação generalizada em diferentes campos das ciências naturaise exatas, sendo: função linear, quadrática, cúbica, e os modelos de crescimento exponencial, Gauss e Lorentz (Tabela 1). Optou-se por estes modelos devido a praticidade de aplicação em função das variáveis exigidas e dos resultados gerados, sendo estas equações frequentemente citadas na literatura onde são discutidas metodologias para estimativa do IAF de plantas, como em Gonzalez-Sanpedro et al. (2008).

Tabela 1. Denominação e representação dos modelos de equações ajustadas para a estimativa da área foliar da batata cultivar Ágata. Guarapuava-PR, 2011.

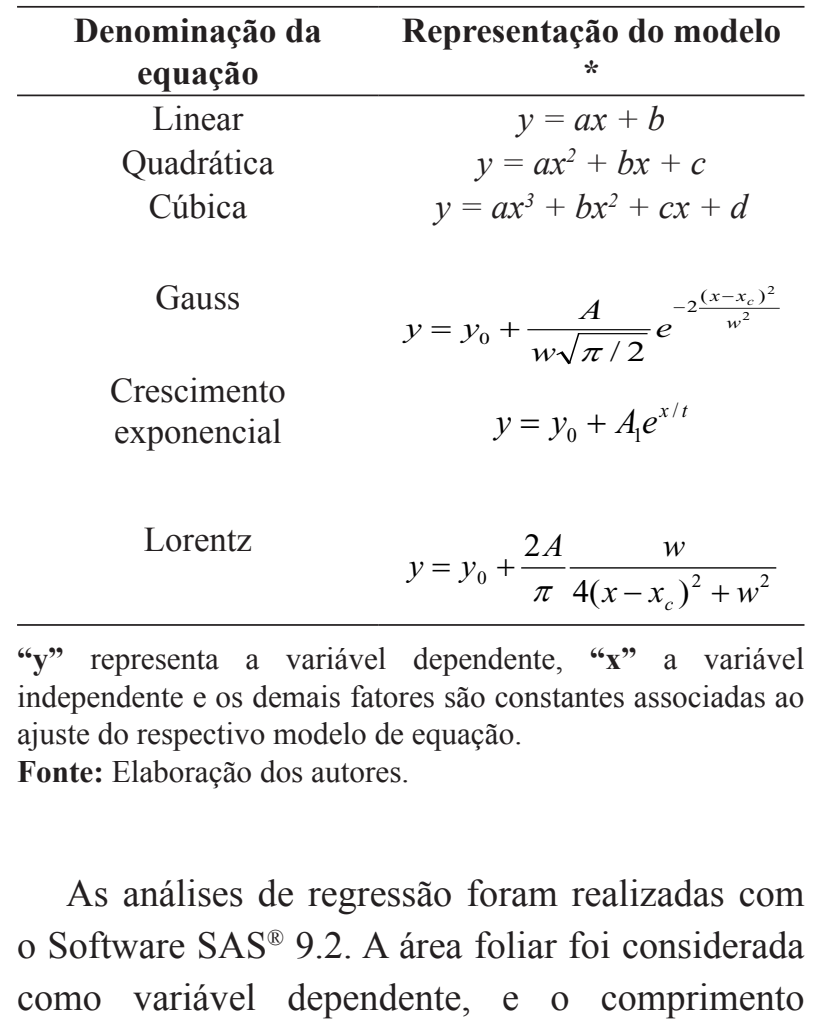

da folha, largura, quociente entre a largura e o comprimento e produto da largura x comprimento, testados como variável independente nos diferentes modelos.As equações obtidas foram avaliadas com base nos coeficientes de correlação (r) e de determinação $\left(\mathrm{R}^{2}\right)$, além da significância com o uso do teste $\mathrm{F}$ ao nível de $95 \%$ de probabilidade.

\section{Resultados e Discussão}

Nas análises realizadas relacionando a área foliar com o comprimento, largura, quociente da largura/ comprimento e razão da largura $x$ comprimento foi verificado que o comprimento foi o parâmetro que apresentou estimativas mais satisfatórias de área foliar, tanto para aplicação direta (Tabela 2) como considerando o produto do comprimento $\mathrm{x}$ largura da folha (Tabela 3), conforme se verifica em ambos os casos,pela significância estatística de todos os modelos testados.

Para estes parâmetros, embora exista significância para as equações ajustadas, observa-se que quando foi utilizado diretamente o comprimento da folha, os coeficientes de correlação e determinação foram geralmente mais elevados, demonstrando um ajuste mais adequado, com exceção do modelo exponencial de crescimento. Entretanto, é pertinente ressaltar que os ajustes derivados da utilização do comprimento x largura foram de alta significância, exceto para a Equação de Lorentz. Neste caso a principal vantagem de se utilizar somente o comprimento da folha reside no fato de se reduzir o tempo necessário para as medições no campo.Este diferencial, referente à obtenção de resultados precisos e de forma rápida na estimativa de área foliar, utilizando o ajuste de equações lineares associado à características dimensionais de folhas foi também observado por Blanco e Folegatti (2003), para as culturas do pepino e tomate. 
Tabela 2. Resultados do ajuste das funções através do parâmetro comprimento, para estimativa da área foliar da batata cultivar Ágata. Guarapuava-PR, 2011.

Variável independente: Comprimento da folha

\begin{tabular}{|c|c|c|c|c|}
\hline Função & Equação ajustada & $\mathbf{R}^{2}$ & $\mathbf{r}$ & Prob $>F$ \\
\hline Linear & $y=19,59 x-145,66$ & 0,97 & 0,99 & $0,00229 *$ \\
\hline Quadrática & $\mathrm{Y}=-59,93+6,68 x+0,48 \mathrm{x}^{2}$ & 0,98 & 0,99 & $0,00277^{*}$ \\
\hline Cúbica & $y=43,59-18,73 x+2,40 x^{2}-0,045 x^{3}$ & 0,99 & 0,99 & $0,02473 *$ \\
\hline $\begin{array}{l}\text { Crescimento } \\
\text { exponencial }\end{array}$ & $y=-1,98+26,6 e^{\frac{x}{9,19}}$ & 0,66 & 0,79 & $0,00008 *$ \\
\hline Gauss & $y=6299,257+\frac{-880294,40}{111,63 * \sqrt{\frac{\pi}{2}}} e^{-2 \frac{(x-4,277)^{2}}{111,63^{2}}}$ & 0,99 & 0,99 & $0,01395^{*}$ \\
\hline \multirow{2}{*}{ Lorentz } & $2 *\left(-1,9745 * 10^{6}\right)$ & \multirow{2}{*}{\multicolumn{2}{|c|}{$0,950,99$}} & \multirow{2}{*}{$0,01414 *$} \\
\hline & $4(x-4,45)^{2}+168,83^{2}$ & & & \\
\hline
\end{tabular}

$\mathrm{R}^{2}=$ coeficiente de determinação; $\mathrm{r}=$ coeficiente de correlação da reta; *significativo $(\mathrm{P}<0,05)$.

Fonte: Elaboração dos autores.

Tabela 3. Resultados do ajuste das funções através do parâmetro produto do comprimento x largura da folha, para estimativa da área foliar da batata cultivar Ágata. Guarapuava-PR, 2011.

\begin{tabular}{|c|c|c|c|c|}
\hline & Variável independente: Produto comprimento $\mathrm{x}$ largura da fo & & & \\
\hline Função & Equação ajustada & $\mathbf{R}^{2}$ & $\mathbf{r}$ & Prob $>\mathbf{F}$ \\
\hline Linear & $y=2,71 x-56,62$ & 0,93 & 0,96 & $0,00068^{*}$ \\
\hline Quadrática & $y=-23,03+1,59 x+0,00704 x^{2}$ & 0,92 & 0,97 & $0,00590 *$ \\
\hline Cúbica & $y=-46,18+3,10 x-0,017 x^{2}+0,000106 x^{3}$ & 0,94 & 0,98 & $0,04595^{*}$ \\
\hline $\begin{array}{l}\text { Crescimento } \\
\text { exponencial }\end{array}$ & $y=35,193 e^{\frac{x}{60,43}}$ & 0,91 & 0,95 & $0,00216^{*}$ \\
\hline Gauss & $y=4257,85+\frac{-5,576}{1022,11 * \sqrt{\frac{\pi}{2}}} e^{-\mathbf{2} \frac{(x-93,97)^{2}}{102 \mathbf{2}^{2}}}$ & 0,90 & 0,96 & $0,02266^{*}$ \\
\hline \multirow{2}{*}{ Lorentz } & $y=502876+\frac{2 *\left(-1,1942 * 10^{7}\right)}{} *$ & \multirow{2}{*}{0,69} & \multirow{2}{*}{0,87} & \multirow{2}{*}{$0,02275^{*}$} \\
\hline & $4(x+86,05)^{2}+1486,78^{2}$ & & & \\
\hline
\end{tabular}

$\mathrm{r}=$ coeficiente de determinação; $\mathrm{r}^{2}=$ coeficiente de correlação da reta; $*$ significativo $(\mathrm{P}<0,05)$.

Fonte: Elaboração dos autores.

Quando se utilizou como variável independe tanto a largura (Tabela 4) como o quociente gerado entre o comprimento e a largura da folha (Tabela 5), os resultados obtidos foram pouco satisfatórios, com um reduzido número de funções ajustadas apresentando significância estatística, e baixos valores para os coeficientes de correlação e de determinação. Estes resultados diferem dos encontrados por Busatoet al. (2010), que observaram que a utilização da razão do comprimento $\mathrm{x}$ largura da folha proporcionou as melhores estimativas de área foliar para a batata cv. Atlantic. Contudo as cultivares apresentam diferenças em sua características morfológicas, o que pode justificar o resultado. 
Tabela 4. Resultados do ajuste das funções através do parâmetro largura da folha, para estimativa da área foliar da batata cultivar Ágata. Guarapuava-PR, 2011.

\begin{tabular}{|c|c|c|c|c|}
\hline & Variável independente: Largura da folha & & & \\
\hline Função & Equação ajustada & $\mathbf{R}^{2}$ & $\mathbf{r}$ & Prob $>$ F \\
\hline Linear & $y=93,91 x-293,64$ & 0,78 & 0,91 & $0,01200 *$ \\
\hline Quadrática & $152,51-114,6 x+23,07 x^{2}$ & 0,83 & 0,94 & $0,03180 *$ \\
\hline Cúbica & $y=-1235,86+894,93 x-2009,49 x^{2}+17,12 x^{3}$ & 0,81 & 0,95 & 0,13180 \\
\hline $\begin{array}{l}\text { Exponencial } \\
\text { crescimento }\end{array}$ & $y=4,293^{\frac{x}{1,419}}$ & 0,84 & 0,95 & $0,01088 *$ \\
\hline Gauss & $y=6449,07+\frac{-186098,83}{23,06 * \sqrt{\frac{\pi}{2}}} e^{-2 \frac{(x-2,5314)^{2}}{23,06^{2}}}$ & 0,75 & 0,95 & 0,06860 \\
\hline \multirow{2}{*}{ Lorentz } & $y=7589,54+\frac{2 *(-414411,56)}{2} * \frac{34,81}{2}$ & \multirow{2}{*}{0,75} & \multirow{2}{*}{0,95} & \multirow{2}{*}{0,06883} \\
\hline & $y=/ 589,54+\frac{\pi}{4} * \frac{4(x-2,56)^{2}+34,81^{2}}{4}$ & & & \\
\hline
\end{tabular}

$\mathrm{R}^{2}=$ coeficiente de determinação; $\mathrm{r}=$ coeficiente de correlação da reta; *significativo $(\mathrm{P}<0,05)$.

Fonte: Elaboração dos autores.

Tabela 5. Resultados do ajuste das funções através do parâmetro quociente comprimento/largura da folha, para estimativa da área foliar da batata cultivar Ágata. Guarapuava-PR, 2011.

\begin{tabular}{|c|c|c|c|c|}
\hline & Variável independente: Quociente comprimento / largurada & Iha & & \\
\hline Função & Equação ajustada & $\mathbf{R}^{2}$ & $\mathbf{r}$ & Prob $>$ F \\
\hline Linear & $y=160,73 x-350,10$ & 0,65 & 0,85 & $0,03310^{*}$ \\
\hline Quadrática & $y=1642,43-1273,57 x+247,46 x^{2}$ & 0,66 & 0,89 & 0,08931 \\
\hline Cúbica & $y=-10147,74+11200,87 x-4075,43 x^{2}+491,64 x^{3}$ & 0,68 & 0,93 & 0,18197 \\
\hline $\begin{array}{l}\text { Exponencial } \\
\text { crescimento }\end{array}$ & $y=0,0086 e^{\frac{x}{0,346}}$ & 0,83 & 0,95 & $0,01167^{*}$ \\
\hline Gauss & $y=10259,32+\frac{-10255,63}{9,05 * \sqrt{\frac{\pi}{2}}} e^{-2 \frac{(x-2,5731)^{2}}{9,05^{2}}}$ & 0,49 & 0,89 & 0,13350 \\
\hline \multirow{2}{*}{ Lorentz } & $v=1257540+2 *(-279054,57)$ & \multirow{2}{*}{0,49} & \multirow{2}{*}{0,89} & \multirow{2}{*}{0,13406} \\
\hline & $=125 / 5,40+\frac{\pi}{4(x-2,57)^{2}+14,13^{2}}$ & & & \\
\hline
\end{tabular}

$\mathrm{R}^{2}=$ coeficiente de determinação; $\mathrm{r}=$ coeficiente de correlação da reta; significativo $(\mathrm{P}<0,05)$

Fonte: Elaboração dos autores. 
Considerando estes resultados, verifica-se que embora existam algumas equações com significância estatística adequada para uso da medida da largura de folhas, o comprimento da folha é melhor opção de parâmetro a ser medido no campo para gerar estimativas da área foliar da cultivar de batata Ágata. Resultados similares para o ajuste de variáveis foram observados por Favarinet al. (2002) para estimativas da área foliar da cultura do café.

Em pesquisa com a cultura da batata Gordon, Brown e Dixon (1994) salientam a relevante importância da utilização de determinações não destrutivas para a estimativa da área foliar da cultura, especialmente considerando a sensibilidade das plantas a danos mecânicos causado pela retirada das folhas. Para os autores medidas diretas do comprimento das folhas no campo resultam em estimativas de área foliar de elevada precisão, com resultados similares aos verificados com a utilização de equipamentos mecânicos específicos de medida direta.

O comportamento das equações ajustadas tendo como variável independente o comprimento da folha é apresentado na figura 4. Verifica-se que com exceção da equação de crescimento exponencial o uso do comprimento da folha ocasiona ajustes com elevada correlação. Os resultados mais adequados em relação a este parâmetro são devidos à maior precisão no processo de leituras no campo, pois na medição da largura pode ocorrer a movimentação dos folíolos para dentro ou para fora da folha, alterando o valor obtido para mais ou para menos, o que não ocorre para o comprimento, que é medido sobre nervura central da folha e folíolo central da extremidade distal desta, que são componentes de menor mobilidade no manuseio, o que torna o processo de medição mais fácil e preciso.

As equações testadas apresentam diferentes níveis de complexidade matemática, contudo observando-se as tabelas de 2, 3, 4 e 5, observase que as equações linear e quadrática, embora matematicamente mais simples, resultam em estimativas com coeficientes de ajuste elevados, em geral igual ou superior aos obtidos com as demais equações. Neste caso, considerando-se a maior facilidade de cálculo, estas equações podem ser destacadas em relação a recomendação para aplicação em estimativas de área foliar da batata cultiva Ágata. 
Figura 4. Resultado das funções ajustadas para a determinação da área de folhas de batata cultivar Ágata, utilizando o comprimento da folha como variável independente. Guarapuava-PR, 2011.
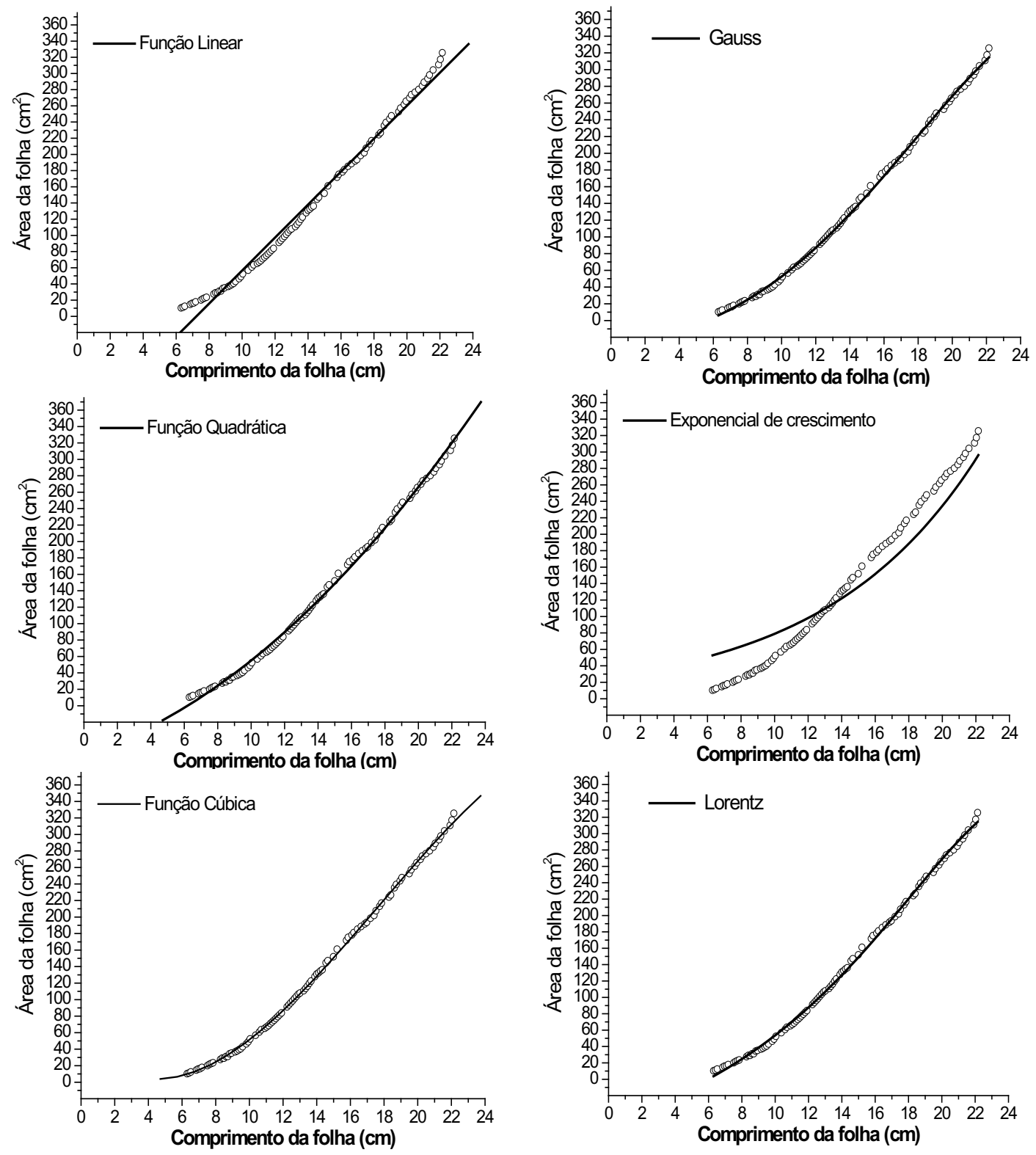

Fonte: Elaboração dos autores.

\section{Conclusões}

Aárea foliar da batata cv. Ágata pode se estimada com precisão através de métodos não destrutivos utilizando-se medidas das dimensões das folhas em diferentes modelos matemáticos lineares.

$\mathrm{O}$ comprimento e o produto do comprimento $\mathrm{x}$ largura da folha são os parâmetros mais adequados para utilização como variável independente na estimativa da área foliar da cultivar de batata Ágata, através modelos matemáticos. Os modelos exponencial de crescimento e Lorentz são os menos indicados por apresentar os menores coeficientes de ajuste. 


\section{Referências}

ADAMI, M.; HASTENREITER, F. A.; FLUMIGNAN, L.; FARIA, R. T. Estimativa de área foliar de soja usando imagens digitais e dimensões foliares. In: SIMPÓSIO BRASILEIRO DE SENSORIAMENTO REMOTO, 13., 2007, Florianópolis. Anais... Florianópolis: INPE, p. 9-14.

BLANCO, F. F.; FOLEGATTI, M. V. A new method for estimating the leaf area index of cucumber and tomato plants. Horticultura Brasileira, Brasília, v. 21, n. 4, p. 666-669, 2003.

BOSCO, L. C.; HELDWEIN, A. B.; BLUME, E.; TRENTIN, G.; GRIMM, E. L.; LUCAS, D. D. P.; LOSSE, L. H.; RADONS, S. Z. Sistema de previsão de requeima em cultivos de batata em santa Maria, RS. Bragantia, Campinas, v. 69, n. 3, p. 649-660, 2010.

BUSATO, C.; FONTES, P. C. R.; BRAUN, H.; BUSATO, C. C. M. Estimativa da área foliar da batateira, cultivar Atlantic, utilizando dimensões lineares. Revista Ciência Agronômica, Fortaleza, v. 41, n. 4, p. 702-708, 2010.

BUSATO, C.; FONTES, P. C. R.; BRAUN, H.; COELHO, F. S.; SILVA, C. C. S.; OLIVEIRA, L. S. Estimativa da área foliar da cultivar de batata Cupido. Horticultura Brasileira, Brasília, v. 27, n. 2, p. 570-573, 2009.

DELLAI, J.; TRENTIN, G.; BISOGNIN, D. A.; STRECK, N. A. Filocromo em diferentes densidades de plantas de batata. Ciência Rural, Santa Maria, v. 35, n. 6, p. 1269-1274, 2005.

FAVARIN, J. L.; DOURADO NETO, D.; GARCIA, A. G.; VILLA NOVA, N. A. Equações para a estimativa do índice de área foliar do cafeeiro. Pesquisa Agropecuária Brasileira, Brasília, v. 37, n. 6, p. 769-773, 2002.

FONTES, P. C. R.; ARAÚJO, C. Adubação nitrogenada de hortaliças: princípios e práticas com o tomateiro. Viçosa: UFV, 2007. 148 p.

GONZALEZ-SANPEDRO, M. C.; LE TOAN, T.; MORENO, J.; KERGOAT, L.; RUBIO, E. Seasonal variations of leaf area index of agricultural fields retrieved from Landsat data. Remote Sensing of Environment, v. 112, n. 3, p. 810-824, 2008.

GORDON, R.; BROWN, D. M.; DIXON, M. A. Nondestructive estimation of potato leaf area index using a fish-eye radiometer. PotatoResearch, Springer Link, v. 37, n. 4, p. 393-402, 1994.

JADOSKI, S. O.; MAGGI, M, F.; LIMA, A. S.; BRUNETTA, L.; WAZNE, R. Sucessão de culturas na fitossanidade e produtividade da cultura da batata
(Solanumtuberosum L.). Pesquisa Aplicada \& Agrotecnologia, Guarapuava, v. 2, n. 1, p. 161-166, 2009.

KÖPPEN, W. Das geographische system der klimate. In: KÖPPEN, W.; GEIGER, R. (Ed.). Handbuch der klimatologie. Berlin: GebruderBorntraeger, 1936. v. 1, p. $1-44$, part C.

LOPES, C. M.; ANDRADE, I.; PEDROSO, V.; MARTINS, S. Modelos empíricos para estimativa da área foliar da videira na casta Jaen. Ciência e Técnica Vitivinícola, Dois Portos, v. 19, n. 2, p. 61-75, 2004.

MALAGI, G.; CITADIN, I.; SCARIOT, S.; REIS, L. Método não destrutivo para determinação da área foliar da videira, cultivar BRS-Violeta. Revista Brasileira de Fruticultura, Jaboticabal, v. 32, n. 4, p. 1250-1254, 2011.

NASCIMENTO, I. B.; FARIAS, C. H. A.; SILVA, M. C. C.; MEDEIROS, J. F.; ESPÍNOLA SOBRINHO, J.; NEGREIROS, M. Z. Estimativa da área foliar do meloeiro. Horticultura Brasileira, Brasilia, v. 20, n. 4, p. 555-558, 2002.

NUNES, J. C. S.; FONTES, P. C. R.; ARAÚJO, E. F.; SEDIYAMA, C. Crescimento da batateira e absorção de macronutrientes influenciados pelos sistemas de preparo de solo e irrigação. Pesquisa Agropecuária Brasileira, Brasília, v. 41, n. 12, p. 1787-1792, 2006.

OLIVEIRA, M. N. S. de; LOPES, P. S. N.; MERCADANTE, M.O.; OLIVEIRA, G. L.; GUSMÃOR, E. Medição da área foliar do pequizeiro utilizando a soma da nervura principal dos folíolos. Unimontes Científica, Montes Claros, v. 3, n. 3, p. 1-7, 2002.

PEREIRA, S. A.; DANIELS, J. (Ed.). O cultivo da batata na região Sul do Brasil. Brasília: Embrapa Informação Tecnológica, 2003. $567 \mathrm{p}$.

SCHEIDT, M. F. C.; STOETZER, A.; BALDIN, I.; KAWAKAMI, J. Efeito da adubação nitrogenada em parâmetros morfológicos de plantas de batata cultivar Ágata em Guarapuava. Horticultura Brasileira, Brasília, v. 27, p. 3228-3231, 2009. Suplemento.

SILVA, M. C. C.; FONTES, P. C. R.; VIANA, R. G. Estimativa da área da folha da batateira utilizando medidas lineares. Horticultura Brasileira, Brasília, v. 26, n. 1, p. 83-87, 2008.

ZUCARELI, C.; RAMOS JUNIOR, E. U.; OLIVEIRA, M. A. de; CAVARIANI, C.; NAKAGAWA, J. Índices biométricos e fisiológicos em feijoeiro sob diferentes doses de adubação fosfatada Semina: Ciências Agrárias, Londrina, v. 31, p. 1313-1324, 2010. Suplemento 1. 